\title{
GASIFIKASI SEKAM PADI (BIONER-1)
}

\author{
Sjaffriadi dan Budi Nurachman \\ Pusat Teknologi Pengembangan Sumberdaya Energi \\ BPPT Gedung II Lantai 22 JI MH Thamrin 8 Jakarta 10340 \\ Email: budi_n@yahoo.com
}

\begin{abstract}
Indonesia has potential abudant biomass wastes. Annual paddy production in Indonesia is approximately 50 million tons, from which 14 tons of rice husks is produced, assuming that each ton paddy could produce 0.28 tons of rice husks. At its calorific value of $12.5 \mathrm{MJ} / \mathrm{kg}$, the annual potential energy provided by these husks is around 175 GJ. A gasification system using rice husk would normally require 1.5 to $2 \mathrm{~kg}$ of rice husks to generate $1 \mathrm{kWh}$ of electricity. Therefore, each ton of rice milled could produce wastes that equals to electricity generation of $150 \mathrm{kWh}$. Rice husk is about 14 to $28.5 \%$ of a rice grain, but mostly has an average value of $25 \%$. A gasification Bioner-1 system is operated 14 hours per day in 366 days per year. This system will drive a rice milling unit for 8 hours per day and produce electricity for villagers for another 6 hours in the evening. At a fuel consumption of $25 \mathrm{~kg}$ per hour, the system will require 130 tons of husks that will be provided from rice fields of around 175 ha. Gas (syngas) produced from the gasification will be used for a dual fuel diesel engine system, supplementing diesel fuel. The diesel fuel substituted by the gas could reach about $75-80 \%$. At a consumption rate of $25 \mathrm{~kg} /$ hour rice husks in the system, the husks consumption per $\mathrm{kWh}$ electricity is $1.5 \mathrm{~kg}(1.5 \mathrm{~kg} / \mathrm{kWh})$ and the efficiency of rice husks conversion is $15 \%$. A small portion of tar could still escape from a gas cleaning system. The tar could be observed during overhoul of the diesel engine. The tar entering into the diesel engine is overcome through switching on the diesel engine for about 10 minutes and flushing using diesel oil right before it is shutted down. Through this method, the tar entering the diesel engine is completely burned.
\end{abstract}

Kata kunci gasification, biomas, rice husk, diesel engine

\section{PENDAHULUAN}

Limbah sekam padi dari proses penggilingan gabah padi menjadi beras dapat di manfaatkan dan dirubah melalui teknologi gasifikasi menjadi bahan bakar (energi) mesin diesel. Selanjutnya mesin diesel mengerakkan generator menghasilkan listrik, menggerakan mesin perontok, mesin pengering dan penggilingan gabah padi. Keberadaan teknologi gasifikasi yang memanfaatkan limbah sekam padi sebagai bahan bakar merupakan salah satu solusi mengatasi masalah lingkungan emisi $\mathrm{CO}_{2}$

Indonesia menyimpan potensi limbah biomasa yang besar. Produksi padi sekitar 50 juta ton padi dan setiap ton gabah menghasilkan 0,28 ton sekam, dalam setahun diperoleh 14 juta ton limbah sekam padi, nilai kalor sekam padi $12,5 \mathrm{MJ} / \mathrm{kg}$, potensi penyediaan energi limbah sekam padi 175 juta GJ/tahun. Sistem gasifikasi sekam padi umumnya membutuhkan $1,5-2,0 \mathrm{~kg}$ sekam padi untuk membangkitkan listrik sebesar
$1 \mathrm{kWh}$. Sehingga dari setiap penggilingan padi 1 ton akan menghasilkan limbah yang setara dengan jumlah energi listrik $150 \mathrm{kWh}$.

Sistem gasifikasi Bioner-1 berbahan bakar sekam padi yang telah dikembangkan berskala $18 \mathrm{kWh}$, memproduksi gas mampu bakar yang dapat digunakan sebagai pengganti solar untuk bahan bakar mesin diesel, untuk menggerakan generator menghasilkan listrik dan mesin penggilingan padi. Sistem ini telah dioperasikan sepanjang tahun( 366 hari) selama 14 jam per hari, yaitu 8 jam pada siang hari untuk menggerakan penggilingan padi dan generator pembangkit listrik 6 jam pada malam hari yang digunakan sebagai listrik pedesaan. Dengan konsumsi bahan bakar $25 \mathrm{~kg} / \mathrm{jam}$, untuk pengoperasian gasifikasi diperlukan bahan bakar sekam padi 130 ton yang dipasok dari persawahan seluas lebih kurang 175 ha. 


\section{METODOLOGI}

Pembangunan dan pengoperasian gasifier dalam jangka pendek bukan merupakan masalah sulit. Tetapi, sukses komersial sistem gasifikasi sangat tergantung pada operasi jangka panjang dan kehandalan operasi sistem. Beberapa sistem gasifikasi telah gagal setelah kurang dari 199 jam masa operasi sebab terbentuknya tar dalam sistem maupun dalam mesin.

Membongkar mesin merupakan metode yang memakan biaya untuk menentukan apakah suatu gas cukup bersih untuk dioperasikan kembali. Pengetahuan yang cukup tentang kualitas dan kebersihan gas adalah perlu untuk disainer, pengembang, pembeli, dan pengguna gasifier. Dibandingkan dengan generasi pertama mesin gasifikasi sekam padi pada tahun tujuh puluhan (Robert Manurung, 1983), maka pada mesin gasifikasi Bioner-1 telah dilakukan modifikasi untuk menangani sistem pembersihan dan pendinginan gas.

\subsection{Peralatan dan Sistem Gasifikasi Bioner-1}

Skema peralatan gasifikasi Bioner-1 dapat dilihat pada Gambar 1,2,3; Gambar 4, 5 dan Gambar 6 yang terdiri dari 3 (tiga) sistem utama yaitu sistem gasifikasi (gasifier/reaktor gasifikasi), sistem pembersihan dan pendinginan gas dan sistem pembangkit tenaga listrik (diesel engine).

Reaksi gasifikasi berlangsung di dalam gasifier (reaktor) dimana gas dihasilkan. Sekam padi di umpankan secara kontinyu pada bagian atas gasifier yang terbuka dan mengalir turun kebawah karena pengaruh gravitasi. Udara sebagai media gasifikasi masuk melalui pori/celah ungun sekam padi. Pada awalnya, produk gas dikeluarkan dari sistem gasifikasi Bioner-1 dengan menggunakan tabung Venturi. Setelah sekitar $10-15$ menit produk gas ditarik ke dalam motor diesel karena daya isap mesin diesel. Produk gas dari gasifier yang masih mengandung debu, tar, dan uap air, dibersihkan dan didinginkan pada sistem pembersihan dan pendinginan gas. Sistem pembersihan dan pendinginan gas terdiri dari cyclone, filter, cooler (heat exchanger), dan scrubber. Gas bersih yang keluar dari sistem pembersih dan pendingin gas digunakan sebagai bahan bakar motor diesel subsitusi diesel/solar (Gambar 7 Sistem distribusi gas dan minyak solar kedalam motor diesel).

Pemakaian gas hasil gasifikasi untuk motor diesel masih membutuhkan sejumlah kecil minyak solar. Sistem distribusi gas dan minyak solar dapat dilihat pada Gambar 7. Motor diesel yang digunakan untuk menghasilkan listrik adalah motor diesel tipe F 3L 912 (Tabel 2).

Pengujian sistem gasifikasi dilakukan dengan presentasi gas yang dapat menggantikan bahan bakar minyak diesel. Pengujian dilakukan dengan mengamati dan menghitung bahan bakar minyak diesel yang tergantikan/ disubsitusi oleh gas hasil gasifikasi seperti dapat dilihat pada Gambar 6 mengenai subsitusi minyak diesel / solar terhadap waktu operasi ).

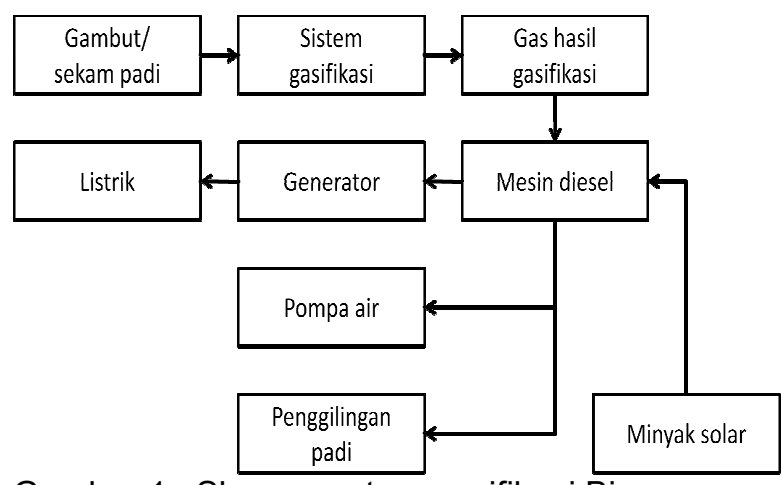

Gambar 1 : Skema system gasifikasi Bioner (Sumartono, 1989)

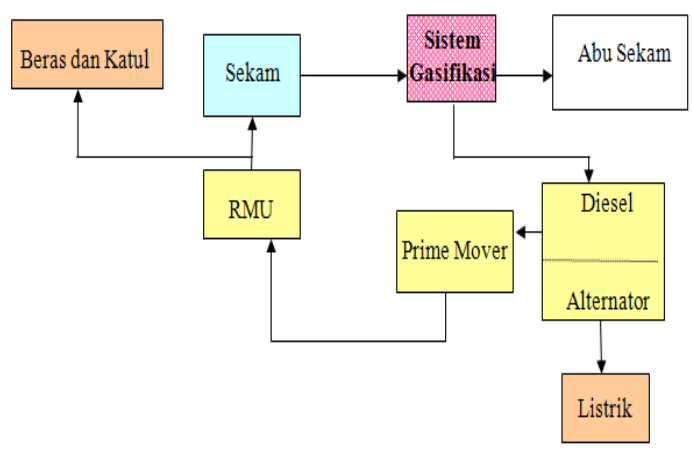

Gambar 2. Pemanfaatan Limbah Sekam Padi untuk Listrik Pedesaan dan Sumber Energi Penggerak Rice Mill Unit (RMU)

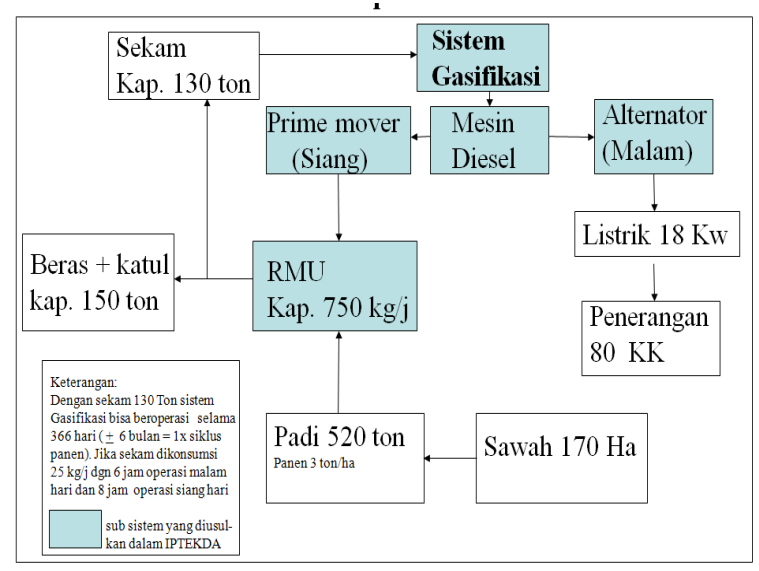

Gambar 3. Skematik operasi sistem gasifikasi untuk 1 (satu) kali siklus Panen (Sjaffriadi, 2003) 


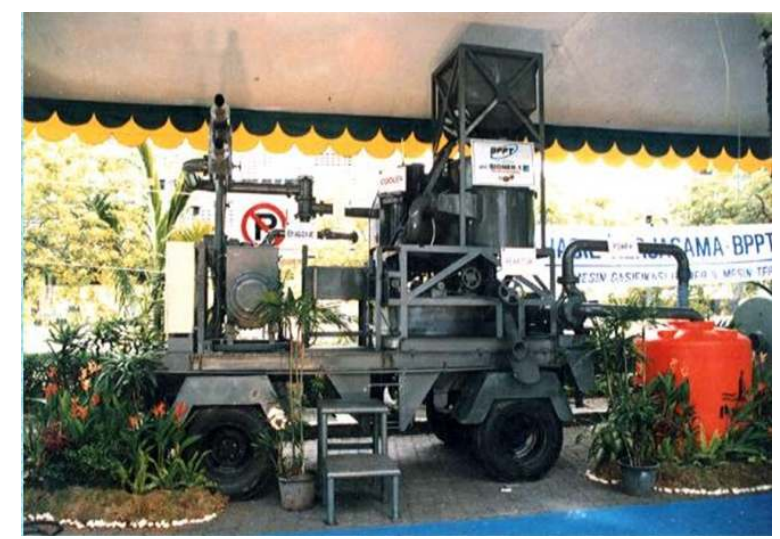

Gambar 4. Gasifikasi Bioner-1 (Sjaffriadi, 1997; 1998; 1999; 2003)

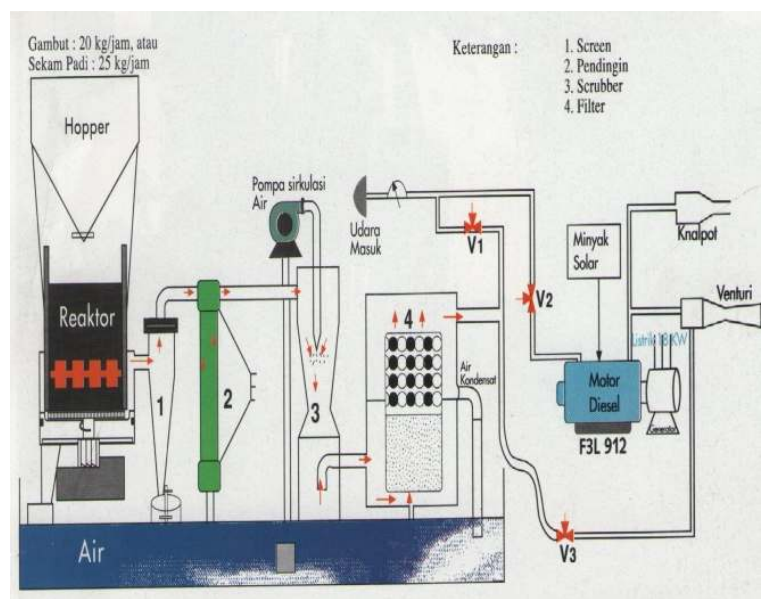

Gambar 5. Sistem peralatan gasifikasi Bioner -1 $18 \mathrm{~kW}$ untuk produksi listrik $18 \mathrm{~kW}$ (Sjaffriadi, 2003)

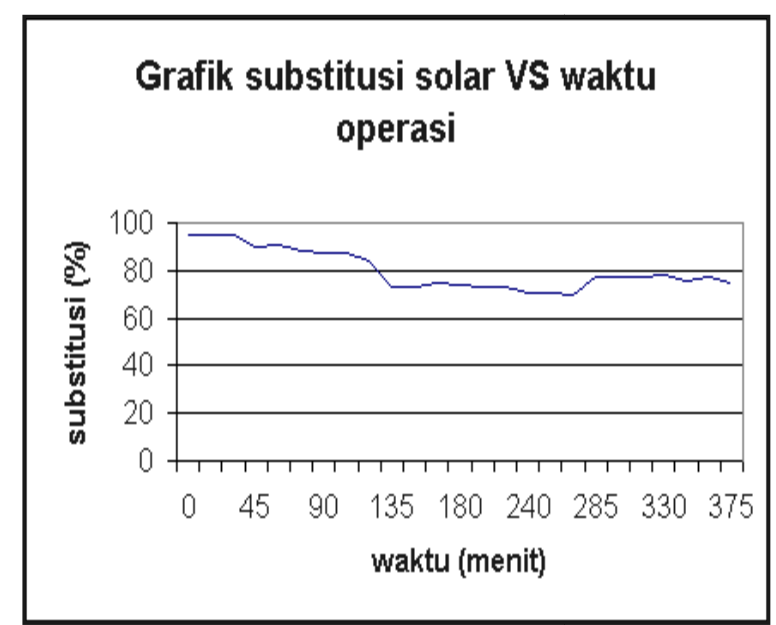

Gambar 6. Grafik subsitusi minyak solar terhadap waktu operasi (Sjaffriadi, 1997; 1998; 1999; 2003)
Tabel 1. Spesifikasi Gasifikasi Bioner-1 (Sjaffriadi, 1997; 1998; 1999; 2003)

\begin{tabular}{|l|l|l|}
\hline & \multicolumn{1}{|c|}{ Engine } & \multicolumn{1}{c|}{ Alternator } \\
\hline Merk & Bisma lisensi & Stamford \\
\hline Tipe & F3L912 & UCL 234 B \\
\hline Daya & $25 \mathrm{~kW}$ & $25 \mathrm{kVA}$ \\
\hline Putaran & $1500 \mathrm{RPM}$ & $1500 \mathrm{RPM}$ \\
\hline Frekwensi & & $50 \mathrm{~Hz}$ \\
\hline Phase & & 3 \\
\hline Power faktor & & 0,8 \\
\hline Voltage & & $380 / 220 \mathrm{~V}$ \\
\hline Ampere & & $3,8 \mathrm{~A}$ \\
\hline Stator WDG & & 0,2 \\
\hline Stator connection & & Star \\
\hline Ambien & & $40^{\mathrm{O}} \mathrm{C}$ \\
\hline Excitation volt & & $27 \mathrm{~V}$ \\
\hline Excitation amps & & $0.9 \mathrm{~V}$ \\
\hline Insolation & & $\mathrm{F}$ \\
\hline
\end{tabular}

Tabel 2. Spesifikasi Genset pada Gasifiksi Bioner - 1

SPESIFIKASI BIONER

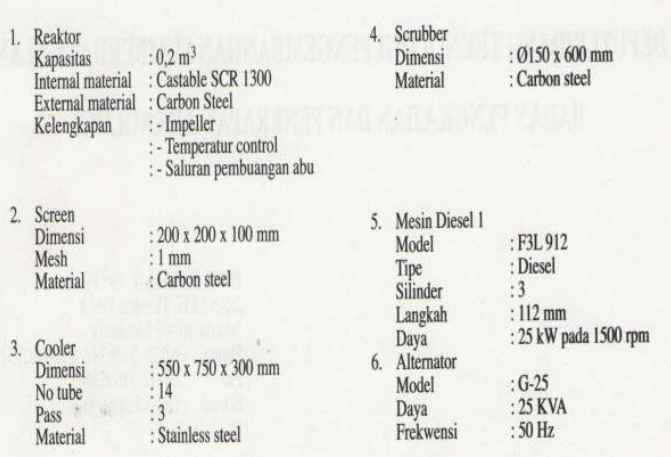

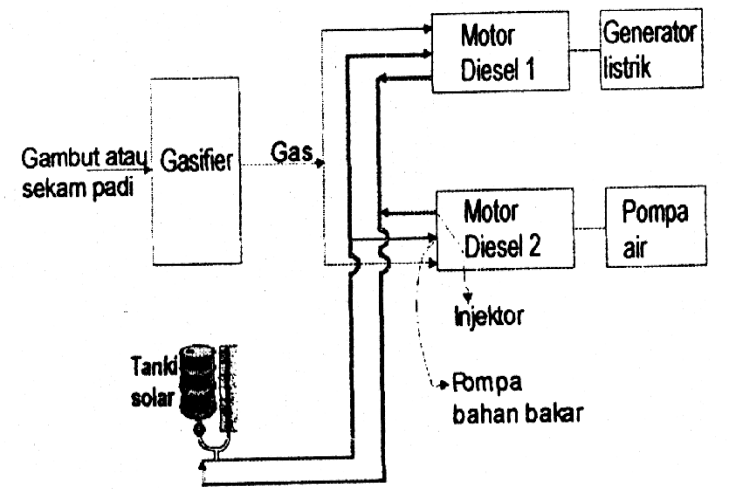

Gambar 7. Sistem distribusi gas dan minyak solar kedalam motor diesel

\subsection{Bahan bakar sekam padi}

Percobaan menggunakan bahan bakar sekam padi pada gasifikasi Bioner-1 digunakan 
sarangan ukuran $10 \mathrm{~mm}$. Sekam padi pada dasarnya merupakan campuran selulosa dan silika sebagai hasil sampingan proses penggilingan padi, Besar kandungan silika bervariasi tergantung keadaan tanah. Kadar air sekam padi sekitar $8-10 \%$, tergantung transpirasi panas, gerakan, dan transportasi oleh udara. Sedangkan nilai kalor sekam padi sekitar 6200 Btu/lb. Sekam padi merupakan $14-28,5 \%$ dari berat gabah varitas padinya, tetapi rata-rata 25 $\%$.

Karakteristik sekam padi dapat dilihat pada Tabel 3 dan Tabel 4 [Sumartono, 1989].

Tabel 3. Komposisi sekam padi

\begin{tabular}{|c|l|c|c|c|}
\hline No & \multicolumn{1}{|c|}{ Unsur } & Satuan & $\begin{array}{c}\text { Pengujian } \\
\text { Lab }\end{array}$ & Kering \\
\hline 1 & Air & $\%$ & 8,18 & - \\
\hline 2 & Abu & $\%$ & 18,44 & 20,09 \\
\hline 3 & Bahan bakar & $\%$ & 59,93 & 66,27 \\
\hline 4 & Karbon & $\%$ & 13,45 & 14,64 \\
\hline 5 & Nilai kalor & Btu/lb & 52,2 & 6755 \\
\hline 6 & Berat jenis & Lb/ft $^{3}$ & 17,26 & - \\
\hline
\end{tabular}

\section{Proses Gasifikasi}

Proses gasifikasi dapat dilihat pada Gambar 8 diagram proses gasifikasi. Abu sisa pembakaran akan dikikis oleh impeller pada reaktor kemudian jatuh sambil disemprot air dari injektor, air tersebut berasal dari bak air yang sebelumnya didinginkan dicooler secara sirkulasi dengan bantuan pompa. Debu dibasahi dengan air tujuannya supaya tidak berham- buran dan mudah pengambilannya dengan screw conveyer untuk memudahkan pembuangannya.

Tabel 4. Komposisi abu sekam padi (Sumartono, 1989)

\begin{tabular}{|c|l|c|}
\hline No & \multicolumn{1}{|c|}{ Unsur } & Kandungan ( \% ) \\
\hline 1 & Silikon oksida & 92,0 \\
\hline 2 & Mgnesium oksida & 2,0 \\
\hline 3 & Mangan Oksida & 0,2 \\
\hline 4 & Fero oksida & 0,1 \\
\hline 5 & Kalsium oksida & 0,1 \\
\hline 6 & Barium oksida & 0,04 \\
\hline 7 & Potasium oksida & 0,02 \\
\hline 8 & Aluminium oksida & 0,01 \\
\hline 9 & Sodium oksida & 0,01 \\
\hline 10 & Tembaga oksida & - \\
\hline 11 & Nikel oksida & $<0,01$ \\
\hline 12 & Karbon & 2,5 \\
\hline 13 & Air & $<3,0$ \\
\hline
\end{tabular}

Temperatur maksimum yang diijinkan gas keluar reaktor $450^{\circ} \mathrm{C}$, tetapi yang normal biasanya berkisar antara $150-350^{\circ} \mathrm{C}$. Gas dari reaktor akan menuju cyclone untuk menangkap debu dan diinjeksikan dengan air kemudian dilewatkan screen kemudian disemprotkan air sebagai pembersih screen. Fungsi screen untuk menangkap debu yang lolos dari cyclone merupakan alat penyaringan yaitu berupa kawat kasa, gas yang tersaring akan terus menuju cooler sedang partikel-partiket yang tersaring akan menempel pada kawat kasa dan terikat air jatuh ke air di bawah.

Pada mesin pendingin gas didinginkan lewat pin tube dengan hembusan udara oleh kipas yang digerakkan V-Belt dari motor diesel. Tujuan didinginkan yaitu selain menurunkan temperatur juga supaya terjadi kondensasi pemisahan antara gas, air dan tar. Dari pendingin gas dialirkan menuju scrubber yang mana gas tersebut disemprot dengan air yang dipompakan dari bak air untuk membersihkan gas dan mendinginkan gas supaya siap untuk dimasukkan ke dalam motor bakar. Gas yang bersih akan naik sedang partikel-partikel ikutan seperti debu abu, air dan tar terikat air yang disemprotkan tadi. Gas yang sudah bersih akan dibersihkan sekali lagi di filter yang media penyaringnya berupa arang kayu. Kemudian dilewatkan pendingin (cooler) dengan media pendingin air tujuan untuk mengkondensasikan uap air dengan tar yang terikat kemudian masuk cyclone untuk memberi kesempatan pada gas untuk terkondensasi secara sempurna. Gas ini sudah siap untuk digunakan dalam campuran dengan bahan bakar solar.

Temperatur gas yang masuk ke motor diesel tidak boleh lebih dari $40^{\circ} \mathrm{C}$. Banyaknya gas yang mengalir ke dalam motor diesel tergantung dari besarnya hisapan. Tekanan dalam sistem gasifikasi biasanya di bawah kondisi atmosfir (vakum). Berdasarkan kondisi tersebut, maka bila terjadi kebocoran, udara dari luar masuk ke dalam sistem dan secara langsung akan mempengaruhi kualitas dan jumlah gas yang masuk ke dalam motor diesel.

Untuk mengatasi kebocoran, psangat perlu diperhatikan batas permukaan air dalam bak jangan sampai kurang dari batas yang ditentukan (10 cm dari bibir bak) sehingga kemungkinan terjadinya kebocoran gas dapat ditekan semaksimal mungkin. 


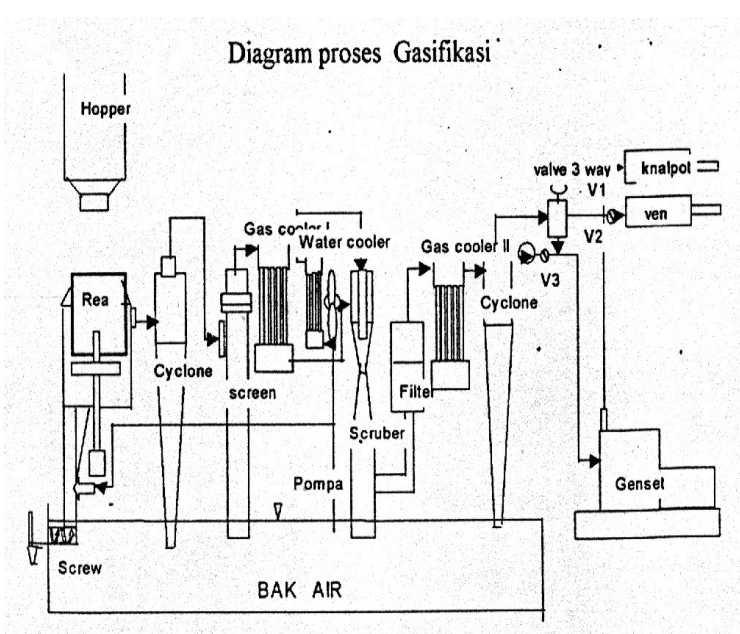

Gambar 8. Diagram proses gasifikasi (Sjaffriadi, 1998; 1999; 2003)

\section{Pembahasan}

Perubahan kualitas dan kuantitas produk gas disebabkan oleh kadar air di dalam bahan baku, komposisi bahan bakar sekam padi dan waktu tinggal bahan bakar dan gas di daerah reduksi di dalam reaktor gasifikasi. Kualitas dan kuantitas udara yang masuk kedalam gasifier sangat besar pengaruhnya pada reaksi $\mathrm{C}+\mathrm{O}_{2} \quad==>\mathrm{CO}_{2}$ karena tinggi rendahnya temperatur di daerah oksidasi di pengaruhi oleh jumlah karbon yang bereaksi dengan oksigen. Hasil monitor temperatur di dalam gasifier digunakan untuk mengontrol dan mengetahui kapan pengisian kembali bahan bakar.

Bahan bakar yang digunakan pada motor diesel tidak hanya yang disuplai dari gasifikasi, tetapi masih memerlukan sejumlah kecil minyak solar supaya penyalaan sendiri (auto ignition) dalam silinder motor masih bisa berlangsung.

Persentasi minyak solar yang di subsitusi gas hasil gasifikasi mencapai $75-80 \%$, dapat dilihat pada Gambar 1 mengenai grafik substitusi minyak solar terhadap waktu operasi. Laju ratarata pemakaian sekam padi $25 \mathrm{~kg}$ per jam. Konsumsi sekam padi per $\mathrm{kWh}$ listrik1,5 kg per $\mathrm{kWh}$ dan efisiensi konversi sekam padi sebesar $15 \%$.

Hilangnya energi (yang tidak terkonversi menjadi listrik ) dalam sistem gasifikasi Bioner -1 disebabkan beberapa konsisi seperti energi terabsorpsi oleh gasifier, terabsopsi sistem pembersih dan pendingin gas dan juga ikut terbawa keluar sistem sebagai gas buang.

Produksi samping berupa tar sebagian kecil masih lolos dari sistem pembersih gas. Produk tar tersebut teramati pada waktu pembongkaran motor diesel. Tar yang masuk kedalam motor disel diatasi dengan penyalaan motor diesel sekitar selama 10 menit pembilasan menggunakan minyak solar menjelang akan dilakukan shut down, dengan cara demikian tar yang masuk ke motor diesel akan terbakar habis.

\section{Kesimpulan}

Hasil percobaan yang telah dilakukan mengindikasikan bahwa gasifikasi Bioner-1 secara teknis layak mengunakan bahan bakar sekam padi untuk menggerakan motor diesel (genset) $18 \mathrm{~kW}$ sebagai penggerak utama penggilingan padi ataupun pompa air.

Efisiensi konversi total $15 \%$, dengan bahan bakar sekam padi menjadi tenaga penggerak genset $25 \mathrm{kVA}$.

Produksi samping tar tidak masalah pada motor diesel, dapat diatasi dengan melkukan pencegahan terhadap kemungkinan terjadinya proses kondensasi tar

\section{DAFTAR PUSTAKA}

Robert Manurung, 1983. Gasifikasi Limbah Pertanian / Kehutanan Menjadi Bahan Bakar Gas Untuk Pembangkit Tenaga listrik $_{2}$ Makalah disajikan pada seminar pemanfaatan limbah pertanian/ perkebunan sebagai sumber energi, Bogor.

Sjaffriadi, 1998. Pembuatan dan Uji Coba Gasifikasi Bioner bahan bakar Sekam Padi untuk Pembangkit Listrik, di Gorontalo. Gorontalo.

Sjaffriadi, 1999. Pembuatan dan Uji Coba Gasifikasi Bioner-1 bahan bakar Sekam Padi untuk Pembangkit Listrik di Pekan Tua, Riau.

Sjaffriadi, 2003. Pembuatan dan Uji Coba Gasifikasi Bioner-1 bahan bakar Sekam Padi untuk Pembangkit Listrik dan penggilingan padi, di Kabupaten Banjar, Kalimantan Selatan .

Sumartono, 1989. Sekam Padi sebagai Sumber Energi (Hasil-hasil Lokakarya, Strategi Penyediaan Energi), Jakarta. 